\title{
Conformational Effects of the A21G Flemish Mutation on the Aggregation of Amyloid $\beta$ Peptide
}

\author{
Maho Yagi-Utsumi*i, and Christopher M. Dobson* \\ Department of Chemistry, University of Cambridge; Lensfield Road, Cambridge CB2 1EW, U.K. \\ Received June 6, 2015; accepted June 27, 2015
}

Among the various hereditary mutants of amyloid $\beta(A \beta)$ in familial Alzheimer's disease (AD), the A21G Flemish-type mutant has unique properties showing a low aggregation propensity but progressive deposition in vascular walls. Moreover, in contrast to other familial AD cases that show extensive $A \beta_{1-42}$ deposition in the brain, patients with Flemish AD predominantly exhibit the deposition of the $A \beta_{1-40}$ isoform. Here we report the structural characterization of the Flemish-type mutant (A21G) in comparison with the wild-type $A \beta_{1-40}$ peptide to examine the possible effects of the A21G mutation on the conformation of the $A \beta_{1-40}$ isoform. The kinetic analysis of the aggregation of the peptides monitored by thioflavin $T$ fluorescence measurement indicates that the mutation precludes the initial nucleation process of amyloid fibril formation by $A \beta_{1-40}$. Spectroscopic data indicate that the Flemish-type mutant bound to aqueous micelles composed of lyso-GM1, in which the mobile N-terminal segment is tethered through the C-terminal helical segment, has reduced $\alpha$-helical structure compared to the wild-type peptide. Our findings suggest that the mutational perturbation to the membrane binding properties is coupled with the changes in nucleation behavior of $A \beta$ during its fibril formation.

Key words amyloid $\beta$; familial Alzheimer's disease; NMR spectroscopy; fibrillization; secondary structure

Alzheimer's disease (AD) and cerebral amyloid angiopathy are characterized by the assembly and deposition of amyloid $\beta(\mathrm{A} \beta)$ peptides, the most abundant of which contain 40 or 42 amino acid residues and are cleaved from a precursor membrane protein by the action of $\alpha$ - and $\beta$-secretases. ${ }^{1,2)}$ These A $\beta$ peptides form cross- $\beta$ amyloid fibrils that bind thioflavin $\mathrm{T}$ (ThT) and are a major component of senile plaques, which are the hallmark of $\mathrm{AD}^{3,4)}$ Although the $\mathrm{A} \beta$ peptides can undergo spontaneous self-assembly in aqueous solution, growing evidence supports the notion that membrane environments, including the presence of ganglioside components, can be key factors involved in the $\mathrm{A} \beta$ assembly process. ${ }^{5-7)}$ Moreover, it has been demonstrated that membranes stimulate nucleation and subsequent aggregation of other pathogenic proteins such as $\alpha$-synuclein. ${ }^{8,9)}$

Various genetic mutations of the $\mathrm{A} \beta$ precursor protein have been identified in familial AD, including those causing a single amino acid substitution in the central tripeptide segment of $\mathrm{A} \beta$ : the Flemish (A21G), Arctic (E22G), Dutch (E22Q), Italian $(\mathrm{E} 23 \mathrm{~K})$, and Iowa (D23N) mutations. ${ }^{10-14)}$ These hereditary A $\beta$ mutants exhibit different physicochemical properties, such as aggregation propensities and ganglioside specificities, which are likely to be associated with AD pathogenesis. ${ }^{15-18)}$ Among the $\mathrm{A} \beta$ variants, the Flemish mutant has unique properties, such as the lowest aggregation propensity, and undergoes progressive deposition in vascular walls resulting in strokes and formation of unusually large senile plaque cores. ${ }^{15,19-21)}$ Moreover, in contrast to other familial AD cases with predominant $\mathrm{A} \beta_{1-42}$ deposition in the brain, the deposits of patients with Flemish $\mathrm{AD}$ contain primarily the $\mathrm{A} \beta_{1-40}$ isoform. ${ }^{19)}$ Therefore, detailed structural characterization of the effects of the

\footnotetext{
${ }^{\dagger}$ Present address: Institute for Molecular Science and Okazaki Institute for Integrative Bioscience, National Institutes of Natural Sciences; 5-1 Higashiyama, Myodaiji, Okazaki, Aichi 444-8787, Japan.
}

A21G mutation on the intrinsic physicochemical property of the $\mathrm{A} \beta$ peptides is crucial for a detailed understanding of the molecular mechanisms underlying the $\mathrm{A} \beta$ assembly process in this form of AD.

Computational simulations have been reported concerning the conformational effects of the $\mathrm{A} 21 \mathrm{G}$ mutation on $\mathrm{A} \beta_{1-40}$ as well as $\mathrm{A} \beta_{1-42} \cdot{ }^{22,23)}$ However, residue-specific experimental characterization of the effects of this mutation in solution by NMR spectroscopy has thus far been limited to artificial constructs: shorter $\mathrm{A} \beta$ fragments containing the mutation site, i.e. $\mathrm{A} \beta_{11-28}{ }^{24,25)}$ and $\mathrm{A} \beta_{21-30}{ }^{26)}$ and a 55-residue fragment of the $\mathrm{A} \beta$ precursor protein ${ }^{27)}$ containing the Flemish-type $\mathrm{A} \beta$. In view of this situation, we here conduct comparative NMR analyses between the Flemish mutant of $\mathrm{A} \beta_{1-40}$ and its wildtype (WT) counterpart and also present the effects of the $\mathrm{A} 21 \mathrm{G}$ mutation on the aggregation behavior of $\mathrm{A} \beta_{1-40}$.

\section{RESULTS AND DISCUSSION}

We prepared the Flemish $\mathrm{A} \beta_{1-40}$ mutant along with the WT protein using recombinant expression systems. First, we compared the aggregation behaviors of these two $\mathrm{A} \beta_{1-40}$ variants by monitoring the time-dependent enhancement of ThT fluorescence during incubation under condition known to stimulate aggregation (Fig. 1). Compared with WT A $\beta$, the Flemish mutant showed a significantly longer lag phase before the onset of fibril formation. This tendency is qualitatively consistent with previous observations reported for the fully oxidized $\mathrm{A} \beta_{1-40}$ variants. ${ }^{20)}$ We then applied a recently developed mathematical protocol ${ }^{28,29)}$ to perform a quantitative analysis of the ThT-fluorescence growth curves of the Flemish mutant and the WT peptide. The results summarized in Fig. 1D indicate that the A21G mutation inhibits the primary nucleation process of A $\beta$ fibrillization.

To examine the possible conformational effects of the A21G 


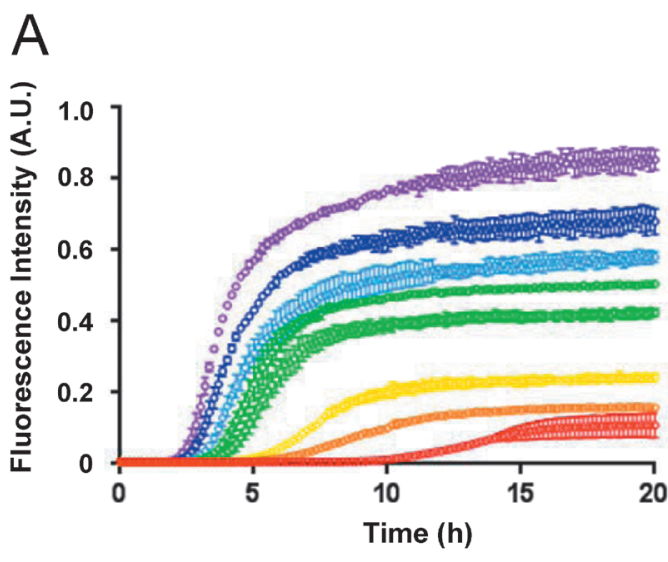

C

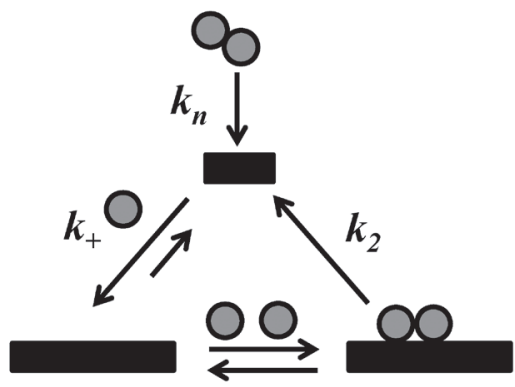

$\mathrm{B}$

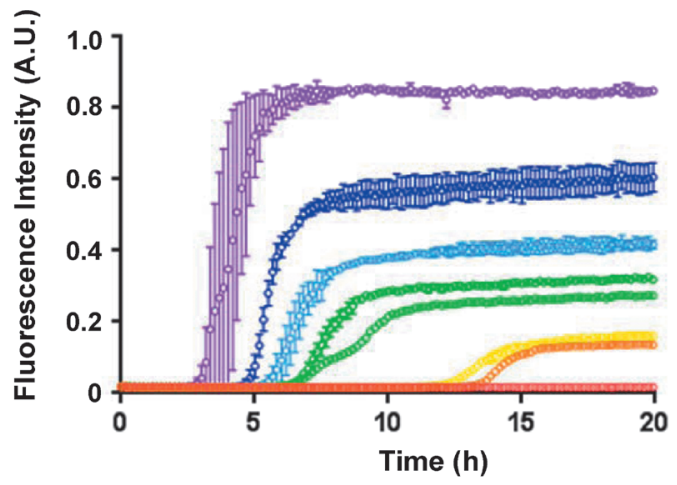

$\mathrm{D}$

\begin{tabular}{|c|c|c|c|c|}
\hline & $\begin{array}{l}\sqrt{k_{+} k_{n}} \\
\left(\mathbf{M}^{-1} \mathbf{s}^{-1}\right)\end{array}$ & $\begin{array}{l}\sqrt{k_{+} k_{2}} \\
\left(\mathbf{M}^{-3 / 2} \mathbf{s}^{-1}\right)\end{array}$ & $\begin{array}{l}k_{n} / k_{2} \\
\text { (nM) }\end{array}$ & $\begin{array}{l}\sqrt{\sqrt{K_{M}}} \\
(\mu M)\end{array}$ \\
\hline WT & $\begin{array}{c}6.3 \times 10^{3} \\
\pm 1.5 \times 10^{3}\end{array}$ & $\begin{array}{c}4.8 \times 10^{7} \\
\pm 8.6 \times 10^{6}\end{array}$ & 0.18 & \pm 1 \\
\hline Flemish & $\begin{array}{c}6.8 \times 10^{2} \\
\pm 1.9 \times 10^{2}\end{array}$ & $\begin{array}{c}5.4 \times 10^{7} \\
\pm 8.6 \times 10^{6}\end{array}$ & 0.016 & $7 \pm 1$ \\
\hline
\end{tabular}

Fig. 1. Changes in the ThT Fluorescence Signals of a Range of Concentrations of WT (A) and Flemish-Type (B) A $\beta_{1-40}$ (Red, $2 \mu \mathrm{m}$; Orange, $4 \mu \mathrm{m}$; Yellow, $6 \mu \mathrm{m}$; Light Green, $8 \mu \mathrm{m}$; Green, $10 \mu \mathrm{m}$; Cyan, $12 \mu \mathrm{m}$; Blue, $15 \mu \mathrm{m}$; and Purple, $18 \mu \mathrm{m}$ ); (C) Summary of the Reaction Scheme; The Rate Constants Are $k_{+}$(Elongation at Fibril Ends), $k_{n}$ (Primary Nucleation in Solution of Order $\mathrm{n}_{\mathrm{c}}$ ), and $k_{2}$ (Secondary Nucleation on the Fibril Surface of Order $\mathrm{n}_{2}$ ); (D) Summary of the Combined Rate Constants Obtained from the Global Fit of Experimental Data to an Equation with Three Free Parameters: $K_{M}$ and the Combinations $k_{+} k_{n}$ and $k_{+} k_{2}$ for the Entire Dataset ( $\mathrm{n}_{2}$ and $\mathrm{n}_{\mathrm{c}}$ Were Set to 2); $\sqrt{K_{M}}$ Gives the Concentration of Half Saturation of Secondary Nucleation

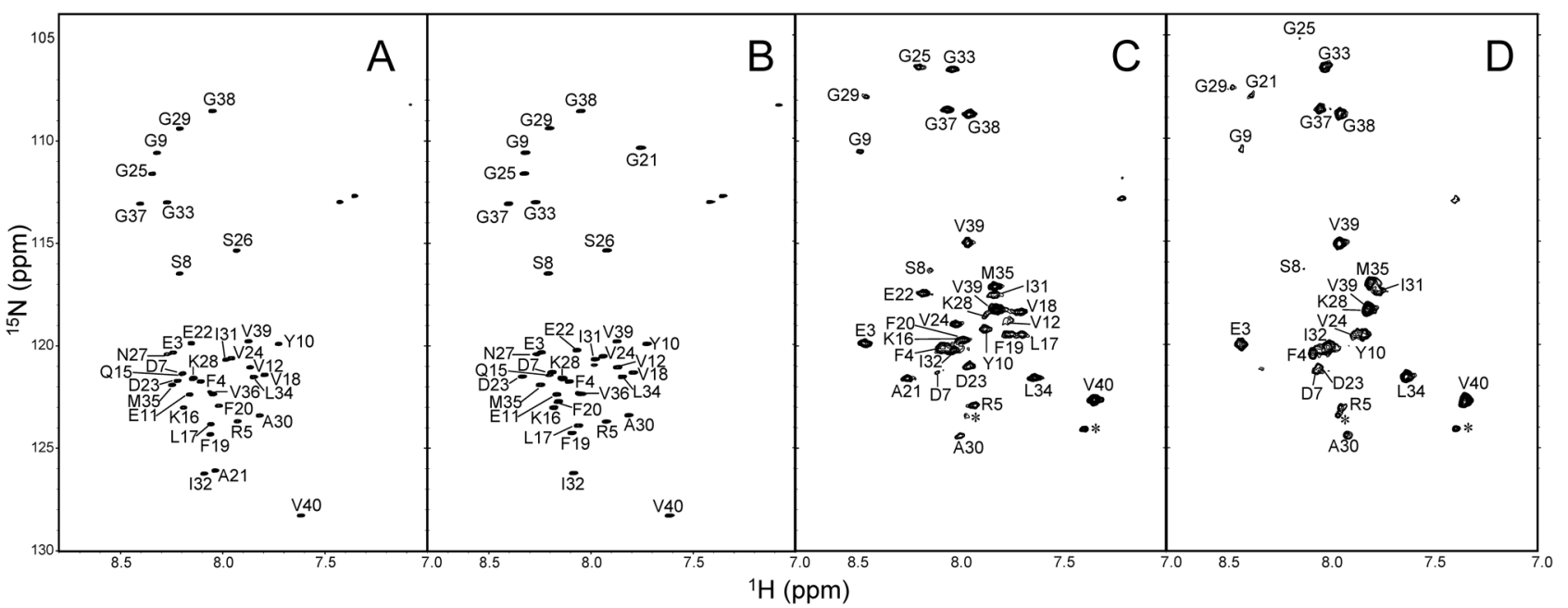

Fig. 2. ${ }^{1} \mathrm{H}-{ }^{15} \mathrm{~N}$ HSQC Spectra of WT (A) and Flemish-Type (B) A $\beta_{1-40}$ and ${ }^{1} \mathrm{H}-{ }^{15} \mathrm{~N}$ TROSY Spectra of WT (C) and Flemish-Type (D) A $\beta_{1-40}$ in the Presence of Lyso-GM1 Micelles; The Asterisk Indicates the Peak Originating from Lyso-GM1

mutation, we conducted NMR analyses of the WT and Flemish $\mathrm{A} \beta_{1-40}$ peptides in their free and micelle-bound forms (Fig. 2). The heteronuclear single quantum coherence (HSQC) spectra of their free forms were quite similar to each other, except for signals originating from the mutation site and residues in its proximity, indicating that the WT and the Flemish $\mathrm{A} \beta_{1-40}$ are both intrinsically disordered in an aqueous solution. In contrast, these two $\mathrm{A} \beta_{1-40}$ peptides exhibited marked differences in their HSQC spectral properties when they were bound to lyso-GM1 micelles, which were used as membrane mimics. In a previous study, we have shown that the WT $\mathrm{A} \beta_{1-40}$ is bound to the micelles at the hydrophilic/hydrophobic interface of gangliosidic clusters, with an up-and-down topology in which two $\alpha$-helices (His14-Val24 and Ile31-Val36) and the C-terminal dipeptide (Val39-Val40) are in contact with the hydrophobic interior and remaining regions are exposed to the aqueous environment. ${ }^{30,31)}$ In the HSQC spectrum of the Flemish mutant, the majority peaks originating from 

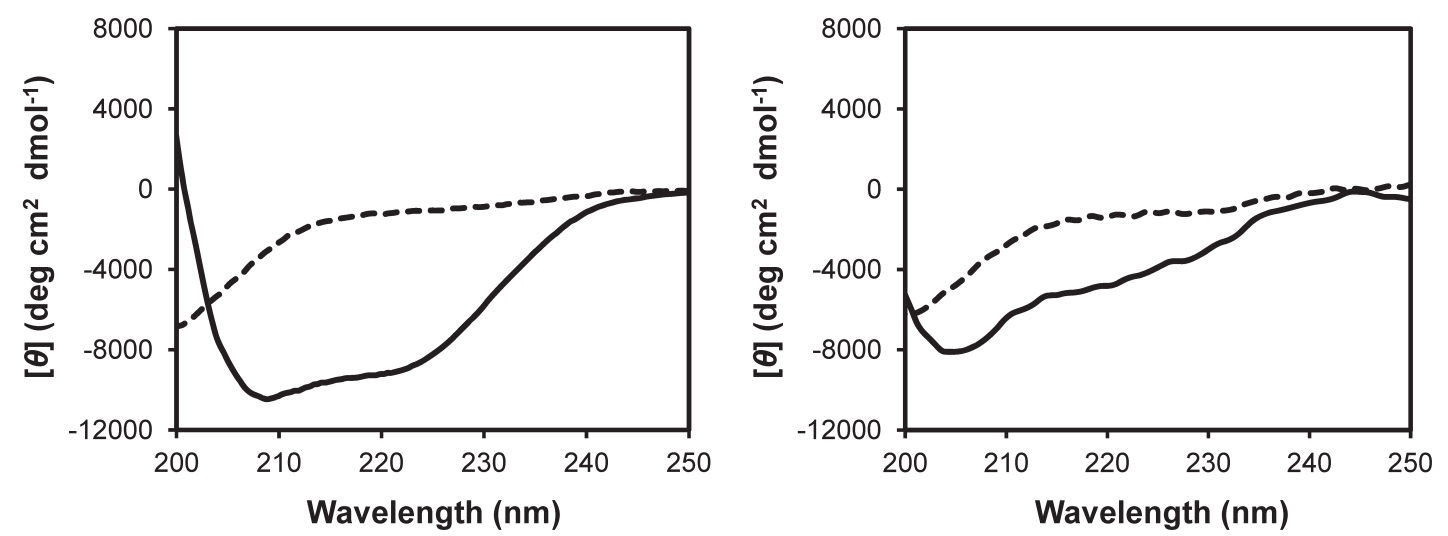

Fig. 3. CD Spectra of WT (A) and Flemish-Type (B) $\mathrm{A} \beta_{1-40}(0.05 \mathrm{~mm})$ Were Recorded in the Absence (Dashed Line) and Presence of Lyso-GM1 $(1.5 \mathrm{~mm})$

the N-terminal Val12-Val24 segment were perturbed, while the WT spectral pattern was preserved for the remaining C-terminal segment. Torsion angle predictions based on the backbone chemical shifts confirmed that the C-terminal segment of the Flemish $\mathrm{A} \beta_{1-40}$ peptide, Ile31-Val36, forms an $\alpha$-helical structure upon binding to lyso-GM1 micelles. These data indicate that the N-terminal segment of the Flemish mutant is in intermediate conformational exchange between different conformational states on the NMR time scale, whereas the C-terminal $\alpha$-helical segment remains tightly bound and acts as a membrane anchor. We also compared circular dichroism (CD) spectral data of the WT and Flemish forms of $\mathrm{A} \beta_{1-40}$ in the presence and absence of lyso-GM1 micelles (Fig. 3). Consistent with the NMR results, the CD data demonstrated that these $\mathrm{A} \beta_{1-40}$ peptides both adopt a significantly $\alpha$-helical conformation upon binding to micelles, but the helical content of the Flemish mutant was considerably lower (11\%) than that of the WT (37\%). These data reveal that the A21G mutation disrupts the first $\alpha$-helix, at His14-Val24, in the membranebound $\mathrm{A} \beta_{1-40}$ molecule. This tendency is consistent with the results of previous studies of the $\mathrm{A} \beta_{11-28}$ fragment in sodium dodecyl sulfate (SDS) micelles. ${ }^{25)}$

In summary, our findings indicate that the glycine residue at position 21 acts as a secondary structure breaker in the Flemish mutant. This finding is consistent with a previously reported molecular dynamics simulation that suggested that this mutation suppresses dimerization of $\mathrm{A} \beta_{1-40}$, in this case mediated by $\beta$-strands. ${ }^{22}$ Thus, it appears that the Flemish mutation in the $\mathrm{A} \beta$ peptide inhibits secondary structure formation upon membrane interaction and self-assembly, both of which are critical steps in the initial nucleation resulting in amyloid plaques. Other important issues, however, remain to be defined including the observation that the fibril formation of the Flemish mutant appears to be specifically promoted through its interaction with ganglioside GD3, which is abundant in vascular walls, ${ }^{17)}$ and the fact that the A21G mutation appears to inhibit aggregation of $\mathrm{A} \beta_{1-42}$ more effectively than that of $\mathrm{A} \beta_{1-40}$ in the clinical states. ${ }^{19)}$ Structural analyses of the putative interactions of the Flemish and other $\mathrm{A} \beta$ variants with their specific gangliosides, and the conformational effects of the $\mathrm{A} 21 \mathrm{G}$ substitution on its different isoforms of $\mathrm{A} \beta$ are currently in progress.

\section{MATERIALS AND METHODS}

Preparation of $\mathbf{A} \boldsymbol{\beta}_{1-40}$ Recombinant $\mathrm{A} \beta_{1-40}$ was expressed and purified as previously described. ${ }^{32)}$ Flemish $\mathrm{A} \beta_{1-40}$ (A21G) was constructed by standard polymerase chain reaction and genetic engineering techniques. It was expressed and purified using the protocol used for WT $\mathrm{A} \beta_{1-40}$. Both $\mathrm{A} \beta_{1-40}$ peptides were dissolved at an approximate concentration of $2 \mathrm{~mm}$ in $0.1 \%(\mathrm{v} / \mathrm{v})$ ammonia and then collected and stored in aliquots at $-80^{\circ} \mathrm{C}$ until use.

Kinetic Assays For kinetic experiments, aliquots of purified WT and Flemish-type $\mathrm{A} \beta_{1-40}$ were subjected to sizeexclusion chromatography on a Superdex 75 column (GE Healthcare) in $20 \mathrm{~mm}$ potassium phosphate buffer, $\mathrm{pH}$ 7.2. The fraction corresponding to the center of the monomer peak was collected and used to prepare, by dilution, a series of samples of concentrations between 2 and $18 \mu \mathrm{M}$ on ice. Protein concentrations were quantitated using the Bradford assay. ${ }^{33)}$ All samples contained $70 \mu \mathrm{M}$ ThT. Each sample $(100 \mu \mathrm{L}$ per well) was then placed into a well of a 96-well half-area plate (Corning 3881). Assays were performed at $37^{\circ} \mathrm{C}$ under quiescent conditions in a plate reader (Fluostar Omega, BMG Labtech). The ThT fluorescence was measured through the bottom of the plate every $600 \mathrm{~s}$ with excitation and emission filters of $440 \mathrm{~nm}$ and $480 \mathrm{~nm}$, respectively. The ThT fluorescence was followed for 2-3 repeats of each monomer concentration. The kinetic data were fitted using the online aggregation fitter (http://www.amylofit.ch.cam.ac.uk/), which is based on a basin-hopping algorithm. ${ }^{28,29)}$

Preparation of Micelles Powdered lyso-GM1 (TaKaRa Bio Inc.) was suspended at a concentration of $12 \mathrm{~mm}$ in $10 \mathrm{~mm}$ potassium phosphate buffer, $\mathrm{pH}$ 7.2, and then mixed by vortexing

NMR Measurements Isotopically-labeled WT and Flemish-type $\mathrm{A} \beta_{1-40}$ were dissolved at a concentration of $0.2 \mathrm{~mm}$ in $10 \mathrm{~mm}$ potassium phosphate buffer containing $10 \%(\mathrm{v} / \mathrm{v})^{2} \mathrm{H}_{2} \mathrm{O}$ in the presence and absence of $6 \mathrm{~mm}$ lyso-GM1. NMR spectral measurements were made on a JEOL EC-920 spectrometer as well as a Bruker DMX-500 and AVANCE800 spectrometers equipped with a cryogenic probe. For the free form, the probe temperature was set to $5^{\circ} \mathrm{C}$ in order to prevent possible aggregation. Backbone resonance assignments were obtained using 
2D ${ }^{1} \mathrm{H}-{ }^{15} \mathrm{~N}$ HSQC and the following three dimensional measurements: $\mathrm{HN}(\mathrm{CA}) \mathrm{NNH}, \mathrm{HNCO}, \mathrm{HNCA}$, and $\mathrm{HN}(\mathrm{CO}) \mathrm{CA}$. In the presence of lyso-GM1, 2D ${ }^{1} \mathrm{H}-{ }^{15} \mathrm{~N}$ transverse relaxation optimized spectroscopy (TROSY) spectra, TROSY-type $\mathrm{HNCO}$, and TROSY-type HNCA were measured at $37^{\circ} \mathrm{C}$. The NMR data were processed and analyzed using NMRPipe and SPARKY software. Secondary structural elements were identified using $\delta 2 \mathrm{D}^{34)}$ and TALOS $^{35)}$ software.

CD Measurements $\mathrm{A} \beta_{1-40}$ was dissolved at a concentration of $50 \mu \mathrm{M}$ in $10 \mathrm{~mm}$ potassium phosphate buffer, $\mathrm{pH}$ 7.2 , in the presence and absence of lyso-GM1 micelles. CD spectra were measured at $37^{\circ} \mathrm{C}$ on a Jasco J-725 spectrometer equipped with a $1.0-\mathrm{mm}$ path length quartz cell. Eight scans were averaged for each sample. The averaged blank spectrum was subtracted from that of each sample. The secondary structural contents were analyzed using the program SELCON 3. ${ }^{36}$ )

Acknowledgments We thank Drs. Tuomas Knowles (University of Cambridge) and Koichi Kato (National Institutes of Natural Sciences) for valuable discussions. We are also grateful to Georg Meisl and Dr. Céline Galvagnion for helpful advice. This work was supported in part by a JSPS/the Ministry of Eduction, Culture, Sports, Science and Technology (MEXT) KAKENHI Grant-in-Aid for Yong Scientists (B) (15K21680 to M.Y.-U.), Research Funding for Longevity Sciences (25-19) from the National Center for Geriatrics and Gerontology, the Nanotechnology Platform Program of MEXT of Japan, and the Okazaki ORION project. M. Y.-U. is a recipient of the Naito Foundation Grant for Studying Overseas.

Conflict of Interest The authors declare no conflict of interest.

\section{REFERENCES}

1) Hardy J, Selkoe DJ. The amyloid hypothesis of Alzheimer's disease: progress and problems on the road to therapeutics. Science, 297, 353-356 (2002).

2) Dobson CM. Protein folding and misfolding. Nature, 426, 884-890 (2003).

3) Tycko R. Solid-state NMR studies of amyloid fibril structure. Annu. Rev. Phys. Chem., 62, 279-299 (2011).

4) Lu JX, Qiang W, Yau WM, Schwieters CD, Meredith SC, Tycko R. Molecular structure of $\beta$-amyloid fibrils in Alzheimer's disease brain tissue. Cell, 154, 1257-1268 (2013).

5) Matsuzaki K, Kato K, Yanagisawa K. A $\beta$ polymerization through interaction with membrane gangliosides. Biochim. Biophys. Acta, 1801, 868-877 (2010).

6) Ariga T, McDonald MP, Yu RK. Role of ganglioside metabolism in the pathogenesis of Alzheimer's disease-a review. J. Lipid Res., 49, 1157-1175 (2008).

7) Yanagisawa K. Role of gangliosides in Alzheimer's disease. Biochim. Biophys. Acta, 1768, 1943-1951 (2007).

8) Fantini J, Yahi N. Molecular insights into amyloid regulation by membrane cholesterol and sphingolipids: common mechanisms in neurodegenerative diseases. Expert Rev. Mol. Med., 12, e27 (2010).

9) Galvagnion C, Buell AK, Meisl G, Michaels TC, Vendruscolo M, Knowles TP, Dobson CM. Lipid vesicles trigger $\alpha$-synuclein aggregation by stimulating primary nucleation. Nat. Chem. Biol., 11, 229-234 (2015).

10) Hendriks L, van Duijn CM, Cras P, Cruts M, Van Hul W, van Harskamp F, Warren A, McInnis MG, Antonarakis SE, Martin JJ, Hofman A, Van Broeckhoven C. Presenile dementia and cerebral haemorrhage linked to a mutation at codon 692 of the $\beta$-amyloid precursor protein gene. Nat. Genet., 1, 218-221 (1992).

11) Levy E, Carman MD, Fernandez-Madrid IJ, Power MD, Lieberburg I, van Duinen SG, Bots GT, Luyendijk W, Frangione B. Mutation of the Alzheimer's disease amyloid gene in hereditary cerebral hemorrhage, Dutch type. Science, 248, 1124-1126 (1990).

12) Nilsberth $C$, Westlind-Danielsson A, Eckman CB, Condron MM, Axelman K, Forsell C, Stenh C, Luthman J, Teplow DB, Younkin SG, Naslund J, Lannfelt L. The 'Arctic' APP mutation (E693G) causes Alzheimer's disease by enhanced A $\beta$ protofibril formation. Nat. Neurosci., 4, 887-893 (2001).

13) Grabowski TJ, Cho HS, Vonsattel JP, Rebeck GW, Greenberg SM. Novel amyloid precursor protein mutation in an Iowa family with dementia and severe cerebral amyloid angiopathy. Ann. Neurol., 49, 697-705 (2001).

14) Miravalle L, Tokuda $T$, Chiarle $R$, Giaccone G, Bugiani O, Tagliavini F, Frangione B, Ghiso J. Substitutions at codon 22 of Alzheimer's $\mathrm{A} \beta$ peptide induce diverse conformational changes and apoptotic effects in human cerebral endothelial cells. J. Biol. Chem., 275, 27110-27116 (2000).

15) Murakami K, Irie K, Morimoto A, Ohigashi H, Shindo M, Nagao M, Shimizu T, Shirasawa T. Synthesis, aggregation, neurotoxicity, and secondary structure of various $\mathrm{A} \beta$ 1-42 mutants of familial Alzheimer's disease at positions 21-23. Biochem. Biophys. Res. Commun., 294, 5-10 (2002).

16) Murakami K, Irie K, Morimoto A, Ohigashi H, Shindo M, Nagao M, Shimizu T, Shirasawa T. Neurotoxicity and physicochemical properties of $\mathrm{A} \beta$ mutant peptides from cerebral amyloid angiopathy: implication for the pathogenesis of cerebral amyloid angiopathy and Alzheimer's disease. J. Biol. Chem., 278, 46179-46187 (2003).

17) Yamamoto N, Hirabayashi Y, Amari M, Yamaguchi H, Romanov G, Van Nostrand WE, Yanagisawa K. Assembly of hereditary amyloid $\beta$-protein variants in the presence of favorable gangliosides. FEBS Lett., 579, 2185-2190 (2005).

18) Yamamoto N, Hasegawa K, Matsuzaki K, Naiki H, Yanagisawa K. Environment- and mutation-dependent aggregation behavior of Alzheimer amyloid $\beta$-protein. J. Neurochem., 90, 62-69 (2004).

19) Kumar-Singh S, Cras P, Wang R, Kros JM, van Swieten J, Lubke U, Ceuterick C, Serneels S, Vennekens K, Timmermans JP, Van Marck E, Martin JJ, van Duijn CM, Van Broeckhoven C. Densecore senile plaques in the Flemish variant of Alzheimer's disease are vasocentric. Am. J. Pathol., 161, 507-520 (2002).

20) Meinhardt J, Tartaglia GG, Pawar A, Christopeit T, Hortschansky P, Schroeckh V, Dobson CM, Vendruscolo M, Fandrich M. Similarities in the thermodynamics and kinetics of aggregation of diseaserelated A $\beta(1-40)$ peptides. Protein Sci., 16, 1214-1222 (2007).

21) Bitan G, Vollers SS, Teplow DB. Elucidation of primary structure elements controlling early amyloid $\beta$-protein oligomerization. $J$. Biol. Chem., 278, 34882-34889 (2003).

22) Huet A, Derreumaux P. Impact of the mutation A21G (Flemish variant) on Alzheimer's $\beta$-amyloid dimers by molecular dynamics simulations. Biophys. J., 91, 3829-3840 (2006).

23) Fawzi NL, Kohlstedt KL, Okabe Y, Head-Gordon T. Protofibril assemblies of the arctic, Dutch, and Flemish mutants of the Alzheimer's A $\beta 1-40$ peptide. Biophys. J., 94, 2007-2016 (2008).

24) Juszczyk P, Kolodziejczyk AS, Grzonka Z. Circular dichroism and aggregation studies of amyloid $\beta$ (11-8) fragment and its variants. Acta Biochim. Pol., 52, 425-431 (2005).

25) Rodziewicz-Motowidło S, Juszczyk P, Kołodziejczyk AS, Sikorska E, Skwierawska A, Oleszczuk M, Grzonka Z. Conformational solution studies of the SDS micelle-bound 11-28 fragment of two Alzheimer's $\beta$-amyloid variants (E22K and A21G) using CD, NMR, and MD techniques. Biopolymers, 87, 23-39 (2007).

26) Grant MA, Lazo ND, Lomakin A, Condron MM, Arai H, Yamin G, Rigby AC, Teplow DB. Familial Alzheimer's disease mutations alter the stability of the amyloid $\beta$-protein monomer folding nucleus. 
Proc. Natl. Acad. Sci. U.S.A., 104, 16522-16527 (2007).

27) Tang TC, Hu Y, Kienlen-Campard P, El Haylani L, Decock M, Van Hees J, Fu Z, Octave JN, Constantinescu SN, Smith SO. Conformational changes induced by the A21G Flemish mutation in the amyloid precursor protein lead to increased $\mathrm{A} \beta$ production. Structure, 22, 387-396 (2014)

28) Cohen SI, Linse S, Luheshi LM, Hellstrand E, White DA, Rajah L, Otzen DE, Vendruscolo M, Dobson CM, Knowles TP. Proliferation of amyloid- $\beta 42$ aggregates occurs through a secondary nucleation mechanism. Proc. Natl. Acad. Sci. U.S.A., 110, 9758-9763 (2013).

29) Meisl G, Yang X, Hellstrand E, Frohm B, Kirkegaard JB, Cohen SI, Dobson CM, Linse S, Knowles TP. Differences in nucleation behavior underlie the contrasting aggregation kinetics of the $\mathrm{A} \beta 40$ and A $\beta 42$ peptides. Proc. Natl. Acad. Sci. U.S.A., 111, 9384-9389 (2014).

30) Utsumi M, Yamaguchi Y, Sasakawa H, Yamamoto N, Yanagisawa $\mathrm{K}$, Kato K. Up-and-down topological mode of amyloid $\beta$-peptide lying on hydrophilic/hydrophobic interface of ganglioside clusters. Glycoconj. J., 26, 999-1006 (2009).

31) Yagi-Utsumi M, Kameda T, Yamaguchi Y, Kato K. NMR character- ization of the interactions between lyso-GM1 aqueous micelles and amyloid $\beta$. FEBS Lett., 584, 831-836 (2010).

32) Yagi-Utsumi M, Matsuo K, Yanagisawa K, Gekko K, Kato K. Spectroscopic characterization of intermolecular interaction of amyloid $\beta$ promoted on GM1 micelles. Int. J. Alzheimer's Dis., 2011, 925073 (2010).

33) Bradford MM. A rapid and sensitive method for the quantitation of microgram quantities of protein utilizing the principle of proteindye binding. Anal. Biochem., 72, 248-254 (1976).

34) Camilloni C, De Simone A, Vranken WF, Vendruscolo M. Determination of secondary structure populations in disordered states of proteins using nuclear magnetic resonance chemical shifts. Biochemistry, 51, 2224-2231 (2012).

35) Cornilescu G, Delaglio F, Bax A. Protein backbone angle restraints from searching a database for chemical shift and sequence homology. J. Biomol. NMR, 13, 289-302 (1999).

36) Sreerama N, Woody RW. Estimation of protein secondary structure from circular dichroism spectra: comparison of CONTIN, SELCON, and CDSSTR methods with an expanded reference set. Anal. Biochem., 287, 252-260 (2000). 